POLLACK PERIODICA

An International Journal for Engineering and Information Sciences

DOI: $10.1556 / 606.2018 .13 .1 .10$

Vol. 13, No. 1, pp. 113-124 (2018)

www.akademiai.com

\title{
ENVIRONMENTAL ASSESSMENT OF THE OPERATION OF WASTEWATER TREATMENT PLANTS
}

\author{
${ }^{1}$ Mária DUBCOVÁ, ${ }^{2}$ Kristína GALBOVÁ, ${ }^{3}$ Ivona ŠKULTÉTYOVÁ \\ Department of Sanitary and Environmental Engineering, Faculty of Civil Engineering \\ Slovak University of Technology in Bratislava, Radlinského 11, 81005 Bratislava, Slovakia \\ e-mail: ${ }^{1}$ maria.dubcova@stuba.sk, ${ }^{2}$ kristina.galbova@stuba.sk, ${ }^{3}$ ivona.skultetyova@stuba.sk
}

Received 22 December 2016; accepted 14 November 2017

\begin{abstract}
The essence of the application of the life cycle assessment study is to avoid increasing the quality of individual products and services at the expense of environmental degradation. Life cycle assessment is regarded as a universal method that is useful for any organization, regardless of the nature and scope of business. The effectiveness of wastewater treatment can determine and assesses potential risks associated with operation of wastewater treatment plant to the environment using appropriate methodology. The implementation of the method requires formulizing processes, using exact methods, allowing identifying the environmental impacts on the environment. Life cycle assessment belongs in industrialized and environmentally conscious states among ordinary tool of environmental management.

The scientific part is the introduction of general standards for specific wastewater treatment plant. The emphasis is given on correct understanding of the problem, regarding the definition of objectives, functional unit, system boundaries, and evaluation indicators. Based on the monitoring and measurement of pollutants in samples of wastewater, the data is processed by the competent life cycle assessment software.
\end{abstract}

Keywords: Life cycle assessment, Wastewater treatment plant, Sustainable production, Environment, Methodology

\section{Introduction}

With the development of society, urbanization and industry, the company is facing the urgent need for greater protection of the environment by minimizing negative impacts. Aside of strict legislative processes the application of voluntary tools of environmental politics is being included into the basis of business strategies, one of 
which is assessment of life cycle of products - Life Cycle Assessment (LCA) analysis. The essence of application of LCA analysis is to avoid the impact of the increasing quality of individual products and services at the expense of environmental degradation [1].

There is a number of general development projects of LCA methods in the territory of the Slovak Republic. Those projects lack the particular concern of development of LCA methods into practice [2]. The principle of LCA methods in the Slovak Republic was mentioned in the waste management of the Slovak Republic in 2005. In the following programs in $2010-2015$, mention of this procedure is missing. From this, it can conclude that despite the fact that this is one of the most effective instruments of voluntary environmental management systems, it is not currently classified in the Slovak Republic as one of the development priorities.

In general, the LCA analysis of wastewater treatment plants is dealing with environmental impact on the cleaning action and subsequent improvement of its operational efficiency. With regard to respect environment it can be argued that the assessment of core benefit of WasteWater Treatment Plant (WWTP) becomes an essential part of the LCA analysis. The essence of the application of the LCA study is to assess the operational fees, benefits and effectiveness of entire process of waste water treatment. LCA is regarded as a universal method that is useful for any organization, regardless of the nature and scope of business. LCA is defined in the international standard EN ISO 14040. The implementation of the method requires processing using exact methods, allowing identifying the environmental impacts on the environment. LCA in industrialized and environmentally conscious states is a common tool in terms of environmental management [3].

The main idea of the application of LCA methods for wastewater treatment, namely sludge produced by the wastewater treatment plant, is to assess the effectiveness and the possibility of treating sludge with a focus on possible negative environmental aspects.

\section{LCA structure based on standard EN ISO 14040}

LCA in standard EN ISO 14040 is defined as the collection and evaluation of the inputs, outputs and impacts on the environment, product-system throughout the life cycle [4].

Key features of LCA are in particular:

- Systematic and adequate response of LCA studies on the environmental aspects of the product and the relations from the extraction of raw materials to final disposal;

- Content and time frame of LCA methods may vary depending on the objective and scope determined;

- Scope, assumptions, methodology, description of data quality and output of LCA studies should be transparent. Sources of information have to be clearly and properly served;

- Depending on the application of LCA studies, confidentiality and ownership relations should be respected; 
- The LCA methodology should be open to new knowledge and improvements at the level of the current state of technology;

- Specific requirements applied to the creation of comparative products used in processing of LCA studies should be accessible to the public;

- It is not recommended to reduce and simplify the LCA results because of the importance of individual relationships and interactions of analyzed systems in different stages of the life cycle;

- There is no uniform method to carry out the LCA analysis. Organizations have the flexibility to use LCA based on the specific use and user requirements.

\section{LCA Framework}

Life cycle assessment consists of defining the objectives and scope, inventory, impact assessment and interpretation of results, as it is shown in Fig. 1. The graphic structure of the LCA framework concludes that findings from one phase may affect the basis of the previous phase, which should be reviewed and then moved over to the next phase. That revision greatly facilitates the use of affordable and suitable software developed for the area.

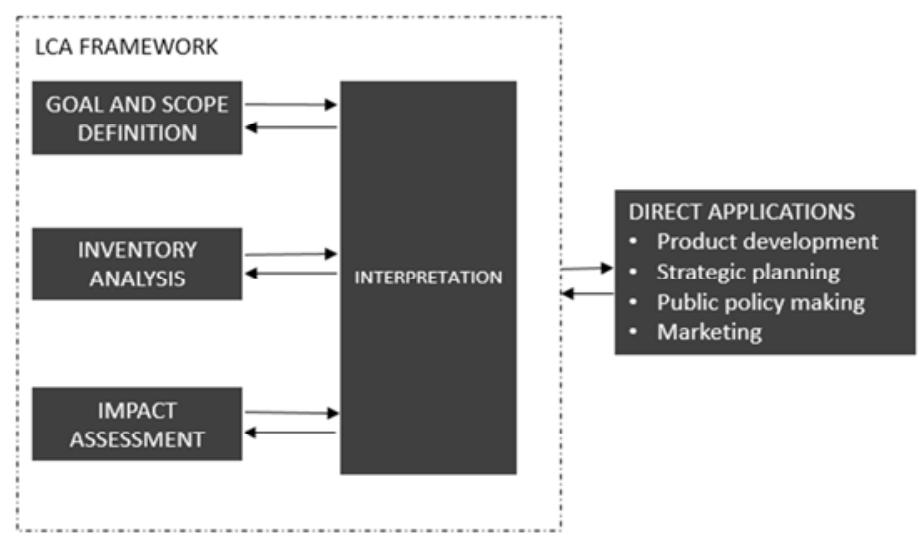

Fig. 1. LCA Framework

\subsection{Goal and scope definition}

The primary purpose of this phase is to identify the functional unit. Its determination is based on a clear assessment of its specification and its function. Determination of functional unit is based on how the function will be specified, quantified and qualified. It is equally necessary to establish the reference rate, representing the quantity of products needed to fulfill the function of a product system. LCA is a complex study that highly requires the determination of boundaries of the system to be specified in the 
initial phase. Precisely, for the same reason, it is necessary to limit the scope of the study. Already at this stage it is important to know what categories and impact assessment methodology will be used [4].

\section{Functional unit}

Functional unit determines the characteristics of the product. The main goal of a functional unit is to ensure the relationship between inputs and outputs. This relationship ensures the comparability of results of the LCA study. Comparability of results is particularly critical in the assessment of the different systems. In that case, comparability must be ensured on the same basis, functional unit has to be identical in all compared systems or subsystems of life cycle. It is important to determine the reference flow for each product systems to meet the required function [4].

Sludge can be evaluated in relation to its weight with respect to the production of sludge at wastewater treatment plant. Within the sludge management and biogas production, the sludge may also be evaluated with respect to the energy $/ \mathrm{kg}$, or in relation to the number of functions that its use complies with (the amount of energy produced). The last type of evaluation permits to LCA studies to include also the cost and inputs to operate the equipment [5].

\section{The scope of the study}

The system boundaries determine which processes will be included in the inventory analysis. They include the processes of energy and material flows related to the system. The systems boundaries can be changed from the treatment studies and demonstrate the relevance of this amendment. Based on standards, mainly sub-flows and processes are taken into account that as inputs and outputs of the main production process, transport, products usage, fuel, energy, waste and recycling, and various additional operations. The criteria used in the study have to be described and understood [4].

While assessing the life cycle of sludge in wastewater treatment plant, so called 'cutoff' criteria have been chosen, that do not include all processes regarding to minimal effect on the final results [6]. Operating and consumption costs were chosen as boundaries. The construction of facilities has not been considered to compare the environmental impact with regard to the content and objectives of the study. An important component of borders constitutes the composition of the sludge with an emphasis on nitrogen and phosphorus content serving for the subsequent quantification of the effects of eutrophication on the environment [5].

When assessing the impact of sludge, we needed schematically to divide WWTP Vráble into systems and subsystems (see Fig. 2). Due to refinement of the analysis, it is necessary to consider the subsystem of biological treatment where sewage enters the process and then the sludge management subsystem.

\subsection{Inventory analysis}

A very important part of the inventory phase is data collection. Data needed for creation of LCA consists of all material and energy flows that enter and exit from the 
life cycle of a product system, especially those that may negatively affect the environment. The main task of inventory modeling of a product system is taking place in specialized software.

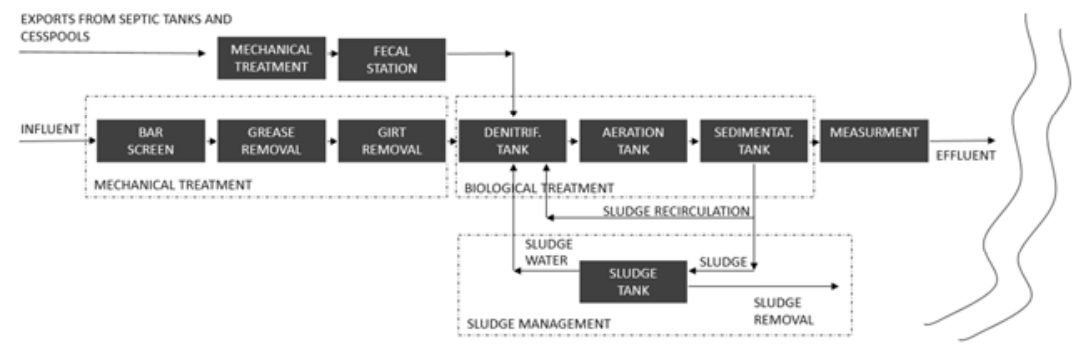

Fig. 2. Systems and Subsystems of WWTP Vráble

Life cycle inventory phase - LCI is used to determine the amount of elementary flows discharged into the environment during the life cycle of a product. Inventory analysis focuses on data collection process, data and methods used to quantify relevant inputs and outputs of the process under consideration [7], [8]. Interpretation has to include an assessment of data quality and sensitivity analysis of relevant inputs and outputs and methodological choices to understand the uncertainty of the results.

Inventory analysis has to assess also:

- well-defined system functions and functional unit;

- properly chosen system boundaries;

- limitation identified in the assessment of data quality and sensitivity analysis.

The results should be interpreted with caution, as they relate to data on inputs and outputs rather than on environmental impacts.

\section{Subsystems of biological treatment}

Sludge produced at wastewater treatment plant Vráble is evaluated throughout the subsystem biological treatment. The evaluation includes the assessment of the functionality and basic parameters in the activation and sedimentation tank, and the subsequent collection and evaluation samples.

\section{Aeration tank}

The aeration tank wastewater treatment plant Vráble underwent the reconstruction in the years 2011-2012 because of a bad condition and increase of the WWTP capacity to 12000 equivalent population. At that time, the surface aerators had low efficiency and were degraded. They failed to aerate the entire volume of the tank creating large dead spots where the sediments formed. That concluded in increasing of operational costs in relation to the cleaning of the tank and problems with sludge. 
Nowadays, the wastewater treatment plant in Vráble consists of two rectangular activation tanks with dimensions $15 \mathrm{~m}$ x $30 \mathrm{~m} \times 3 \mathrm{~m}$. Each tank contains four surface aerators AIRE-O2 Triton. Aerators are located in pairs on steel bridges above the tank. Aerators can rotate $360^{\circ}$ what should provide perfect mixing of the entire volume of the tank. Currently, dead spots are forming in the corners of the tank (Fig. 3 and Fig. 4). These dead spots are cleaned once per year what increases the operating costs.

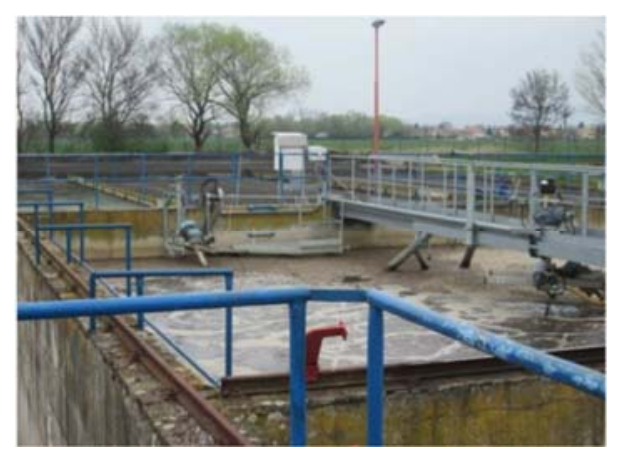

Fig. 3. Aeration tank of WWTP Vráble

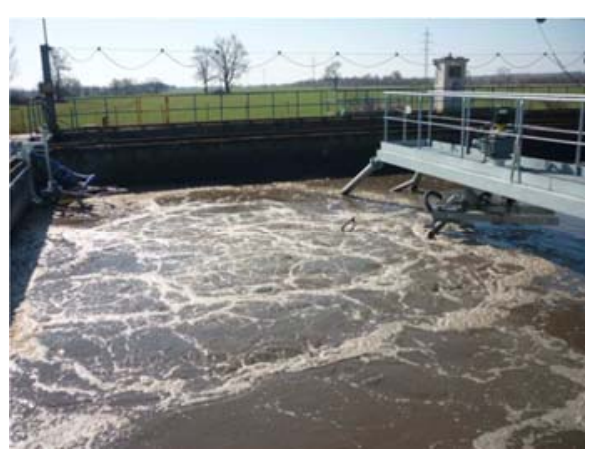

Fig. 4. Aeration tank of WWTP Vráble

The operating volume concentration of the activated sludge depends on the amount of feed of the substrate, the quality of the waste water and the water temperature. To meet the required quality of treated water it is necessary to maintain the aerobic tank of activated sludge concentration in the range of $400-500 \mathrm{ml} / 1$ in dependence on the residual concentration of oxygen. Healthy sludge has good sedimentation properties, during the first 10 minutes, $90 \%$ of the sludge settles to the bottom of the measuring cylinder. It has a dark brown color with earthy odor. The water above the sludge is clear with insignificant amounts of sludge flakes. The sludge that forms springy and slowly settling pads of grey color indicates a fault in the activated process. An excess of foam contact can signal the activation tank metabolic overload, decomposition of waste water, the presence of toxic substances in water or in the presence of bigger amounts of surfactants. Deterioration of the sedimentation properties of activated sludge can cause problems in the technological process of treatment.

Merging or sprouting is depending on the causes called 'disease' of activated sludge. In such cases, it is necessary to reduce the sludge concentration to a minimum and incorporate activation tank again. Sometimes, it is sufficient to stop the inflow of wastewater and the contents of the activation tank are aerated for at least 12 hours without load. After 3 to 6 months wastewater treatment plant operation, the sludge space is filled with conditioned concentrated sludge with a solid content of $3-5 \%$.

\section{Sedimental tank}

Water flows from the aeration tank into two horizontal settling tanks. The tanks are fitted with a reverse sludge pumps and with movable bridge along entire reservoirs for the removal of floating sludge (Fig. 5 and Fig. 6). 


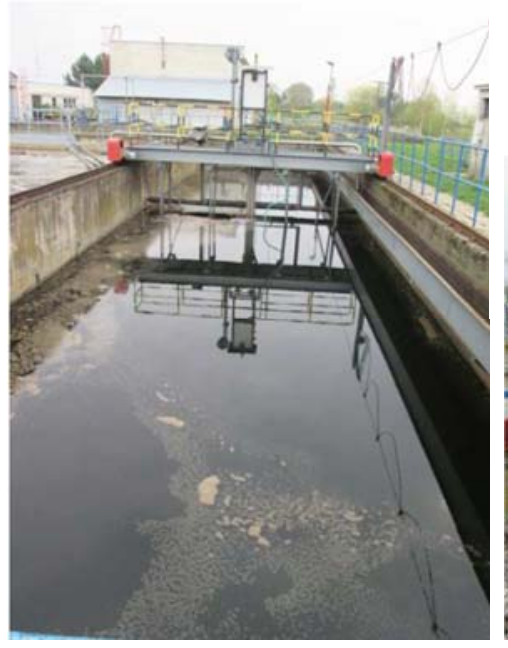

Fig. 5. Sedimental tank of WWTP Vráble

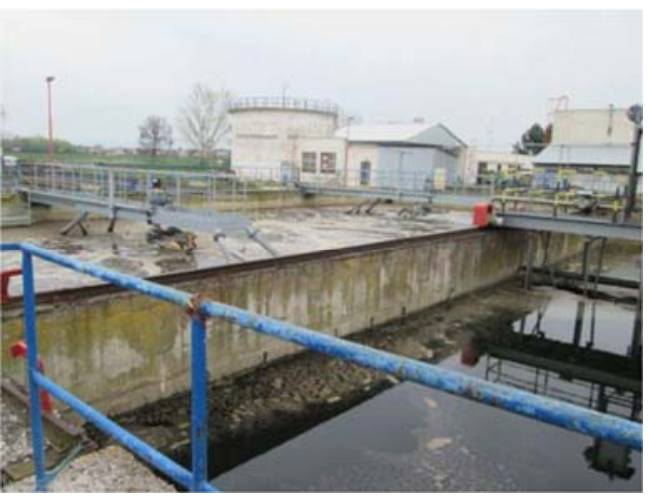

Fig. 6. Sedimental tank of WWTP Vráble

\section{Subsystem of sludge management}

As part of wastewater treatment plant sludge management in Vráble, the excess sludge is stored in the storage tank, which also serves as a digestion chamber. Subsequently, the sludge is pumped to sludge fields (Fig. 7).

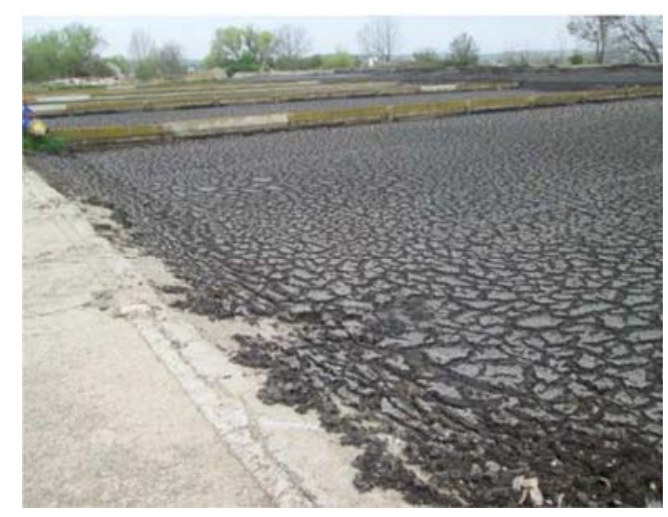

Fig. 7. Sludge fields of WWTP Vráble

\subsection{Data collection}

The amount of sludge production in the inventory phase was followed each month focusing on the production of raw sludge, sludge water, digested sludge and solids. The measured data are processed in the Table $I$. 
Table I

Inventory data of sludge

\begin{tabular}{|c|c|c|c|c|c|c|c|}
\hline Month & 1 & 2 & 3 & 4 & 5 & 6 & 7 \\
\hline Raw sludge $[\mathrm{kg}]$ & 1322 & 1250 & 860 & 840 & 1320 & 1025 & 1160 \\
\hline Sludge water $\left[\mathrm{m}^{3}\right]$ & 550 & 144 & 420 & 120 & 120 & 660 & 180 \\
\hline Digested sludge $[\mathrm{kg}]$ & 0 & 240 & 720 & 600 & 880 & 1040 & 680 \\
\hline Solids [kg] & 18 & 11 & 18 & 12 & 22 & 19 & 68 \\
\hline Month & 8 & 9 & 10 & 11 & 12 & \multicolumn{2}{|c|}{ In total } \\
\hline Raw sludge $[\mathrm{kg}]$ & 1170 & 1170 & 1190 & 1150 & 1280 & \multicolumn{2}{|c|}{13762} \\
\hline Sludge water $\left[\mathrm{m}^{3}\right]$ & 560 & 270 & 490 & 800 & 610 & \multicolumn{2}{|c|}{5014} \\
\hline Digested sludge [kg] & 450 & 560 & 710 & 610 & 520 & \multicolumn{2}{|c|}{18776} \\
\hline Solids [kg] & 18 & 11 & 32 & 32 & 0 & \multicolumn{2}{|c|}{213} \\
\hline
\end{tabular}

\subsection{Interpretation}

Life cycle inventory phase - LCI is used to determine the amount of elementary streams discharged into the environment during the life cycle of a product. Inventory analysis focuses on data collection process and methods used to quantify relevant inputs and outputs of the process under consideration [8]. LCI analysis procedure is shown in Fig. 8 .

An important part of the interpretation may be to carry out special checks. It is always necessary to use simplifications of assumptions and estimates during the modeling and LCA study to continue assessment. These have to be written in the final report together with any solutions, results and conclusions. Their influence is treated and defended with sensitivity analysis, through discussions along with all significant results.

Interpretation of life cycle is the final phase of LCA, which will bring together the findings of the inventory and assessment of environmental impacts in accordance to the stated aim and scope of the study. The output becomes a large variety of values that are necessary to be clearly categorized within the inventory control. The findings arising from the interpretation may take the form of conclusions and recommendations. The actual outputs often need to be supplemented or amended in the previous stages for more accurate LCA study.

Interpretation consists of several steps:

- $\quad$ sorting information from the first three phases;

- checking completeness, sensitivity, and consistency;

- $\quad$ structuring data - creating structuring tables and graphs [5].

\subsection{Impact assessment}

Impact assessment of the life cycle focuses on the design outputs of inventory. The first point of the assessment is the classification of elementary flows to the grouping of individual streams into groups and common categories. After classification, it is necessary the characterization of elementary streams in a specific category [4]. 


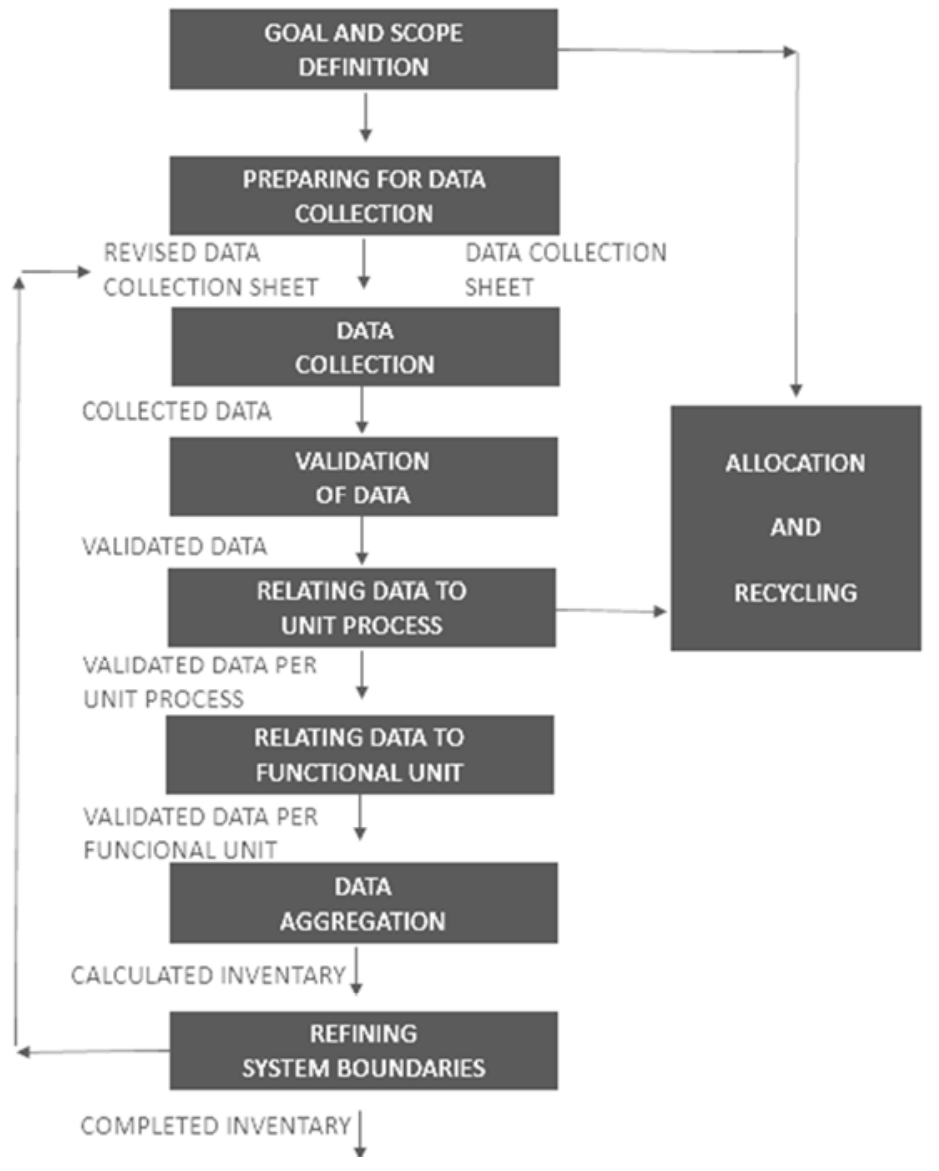

Fig. 8. LCI analysis model

Impact assessment of sewage sludge from wastewater treatment plant Vráble is based on assigning the corresponding characterization factors for each elementary stream. The values from the inventory phase were used, namely the inflow of sewage, effluent from wastewater treatment plant, power consumption and sludge data, as the amount of raw sludge, sludge water, digested sludge and solids. Inventory results were processed using free software OpenLCA using available databases and for evaluating the results. Results from the first chart show the possible environmental impact of sludge management for human health. The greatest negative impact was reflected in consistence on human toxicity $(45 \%)$ and respiratory effects $(53 \%)$. Minimal impact was reflected in parts of the ozone layer depletion, photochemical oxidation and ionizing radiation (Fig. 9).

In the second method of evaluation, we focused on the potential impact of sludge management on the different value of the ecosystem quality (Fig. 10). The greatest 
negative impact was reflected in parts of the climate change $(50 \%)$ and terrestrial ecotoxicity (42\%).

LCAs typically should not be generalized due to subjectivity in the definition of scenarios [9], influence of local conditions [10] and selection of system boundaries [11]. Risch et al. [12] presented the results of an LCA of urban wastewater systems with the objective of quantifying the relative contribution of sewer systems.

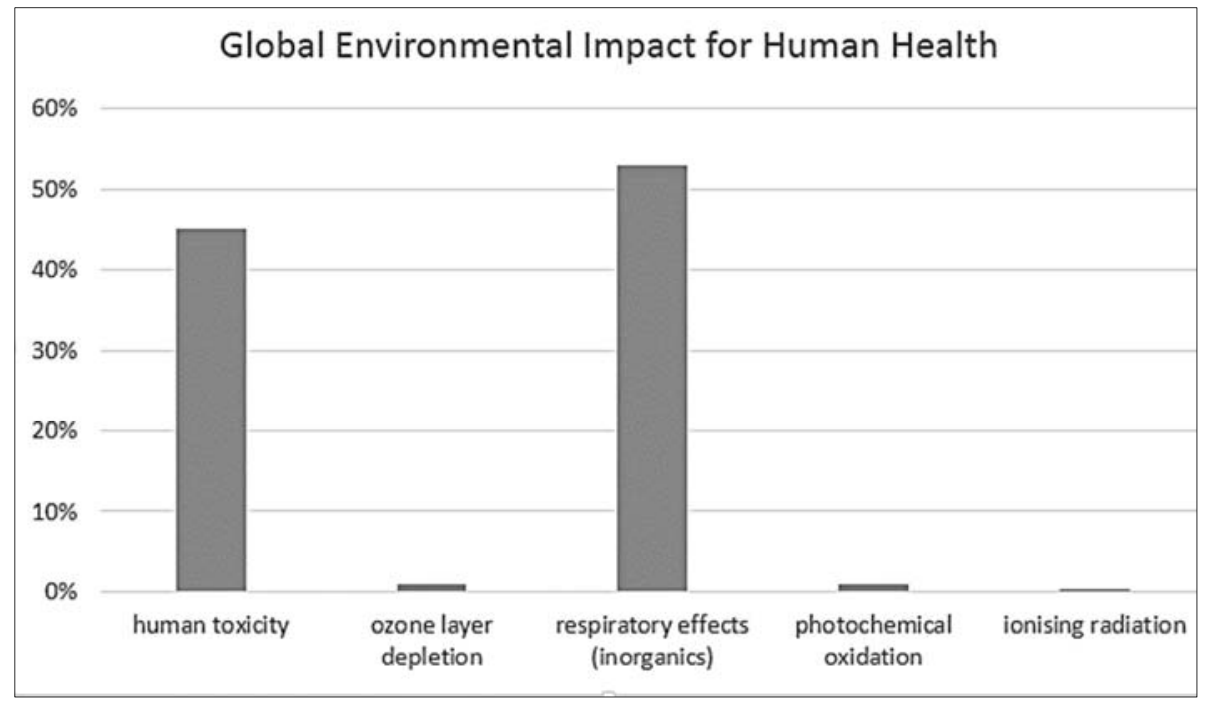

Fig. 9. Global environmental impact for human health

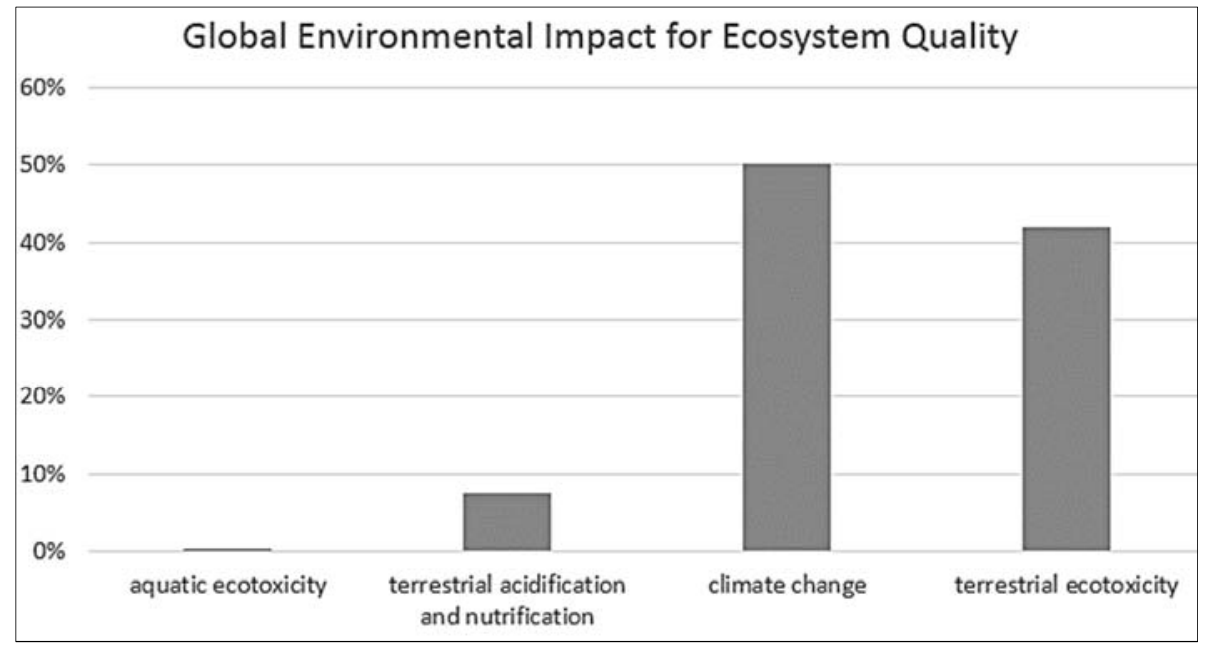

Fig. 10. Global environmental impact for ecosystem quality 


\section{Conclusion}

The goal of this paper was to introduce the issue of the application of LCA and implement methods of sludge from wastewater treatment plant in Vráble. The essence of the method of applying the LCA was to evaluate the potential hazardous effects on the individual components of the environment and the subsequent percentage of the impact. The key to proper implementation is the understanding of the life cycle of sewage sludge in connection with EN ISO 14040. The assessment is based on correct identification of study objectives, scope, system boundaries and functional unit. A significant part of the assessment is based on the legislative limits of individual indicators. In the sludge management it is important to focus on the potential use and disposal of sludge, which can have a negative impact on the environment. The challenge is the determination and analysis of elements which are not provided with sufficient legislation and, therefore, the monitoring is not sufficient.

\section{Acknowledgment}

This work was supported by the Slovak Research and Development Agency under the contract No APVV-0372-12 and by the Scientific Grant Agency with project VEGA No. 1/0631/15 in the Department of Sanitary and Environmental Engineering of Slovak University of Technology in Bratislava.

\section{References}

[1] Leitol C. Multi criteria option analysis in the technology design of mechanical-biological treatment of waste, Pollack Periodica, Vol. 11, No. 2, 2016, pp. 75-86.

[2] Krídlová Burdová E., Vilčeková S. Building environmental assessment - waste management, Pollack Periodica, Vol. 9, No. 1, 2014, pp. 117-125.

[3] Kudláček I., Hejhal T. Ecological overview on material structure of transformer (in Czech), Dielectric and Insulating Systems in Electrical Engineering, Bratislava, Slovak University of Technology, 2004, part 1, pp. 48-52.

[4] ISO 14040:2006, Environmental management, Life cycle assessment, Principles and framework, International S. Organization, 2006.

[5] Kočí V. Assessment of life cycle (in Czech), Water sources, Ecomonitor Comp, Chrudim, Institute of Technology and Business in České Budějovice, 2009.

[6] Hellweg S., Doka G., Finnveden G., Hungerbühler K. Assessing the eco-efficiency of endof-pipe technologies with the environmental cost efficiency indicator, a case study of solid waste management, Journal of Industrial Ecology, Vol. 9, No. 4, 2005, pp. 189-203.

[7] Cashman S., Gaglione A., Mosley J., Weiss L., Hawkins T. R., Ashbolt N. J., Cashdollar J., Xiaobo X., Ma C., Arden S. Environmental and cost life cycle assessment of disinfection options for municipal wastewater, Environmental Protection Agency, Washington DC, 2014.

[8] Stajanča M. Analysis of life cycle as a tool of environmental impact assessment of constructional products (in Czech) 13th Professional Conference of Postgraduate Students, Juniorstav 2011, Brno, Czech Republic, 4 February 2011, pp. 1-6. 
[9] Tascione V., Raggi A. Identification and selection of alternative scenarios in LCA studies of integrated waste management systems: a review of main issues and perspectives, Sustainability, Vol. 4, No. 10, 2012, pp. 2430-2442.

[10] Laurent A., Bakas I., Clavreul J., Bernstad A., Niero M., Gentil E., Hauschild M. Z., Christensen T. H. Review of LCA studies of solid waste management systems, Part I I: lessons learned and perspectives, Waste Manag, Vol. 34, No. 3, 2014, pp. 573-588.

[11] Corominas L., Foley J., Guest J. S., Hospido A., Larsen H. F., Morera S., Shaw A. Life cycle assessment applied to wastewater treatment: state of the art, Water Res, Vol. 47, No. 15, 2013, pp. 5480-5492.

[12] Risch E., Gutierrez O., Roux P., Boutin C., Corominas L. Life cycle assessment of urban wastewater systems: quantifying the relative contribution of sewer systems, Water Res, Vol. 77, 2015, pp. 35-48. 